\title{
Loss of Hepatic Autoregulation after Carbohydrate Overfeeding in Normal Man
}

John N. Clore, Shirley T. Helm, and William G. Blackard

Division of Endocrinology \& Metabolism, Medical College of Virginia/Virginia Commonwealth University, Richmond, Virginia 23298

\begin{abstract}
To determine the effect of increased glycogen stores on hepatic carbohydrate metabolism, 15 nondiabetic volunteers were studied before and after $4 \mathrm{~d}$ of progressive overfeeding. Glucose production and gluconeogenesis were assessed with $\left[2-{ }^{3} \mathrm{H}\right]$ glucose and $\left[6-{ }^{14} \mathrm{C}\right]$ glucose (Study $\left.\mathrm{I}, n=6\right)$ or $[3-$ $\left.{ }^{3} \mathrm{H}\right]$ glucose and $\left[\mathrm{U}_{-}^{14} \mathrm{C}\right]$-alanine (Study II, $n=9$ ) and substrate oxidation was determined by indirect calorimetry. Overfeeding was associated with significant $(P<0.01)$ increases in plasma glucose $(4.97 \pm 0.10$ to $5.09 \pm 0.11 \mathrm{mmol} /$ liter $)$, insulin ( $18.8 \pm 1.5$ to $46.6 \pm 10.0 \mathrm{pmol} / \mathrm{liter})$ and carbohydrate oxidation $\left(4.7 \pm 1.4\right.$ to $\left.18.0 \pm 1.5 \mu \mathrm{mol} \cdot \mathrm{kg}^{-1} \cdot \mathrm{min}^{-1}\right)$ and a decrease in lipid oxidation (1.2 \pm 0.2 to $0.3 \pm 0.1 \mu \mathrm{mol}$ $\left.\mathrm{kg}^{-1} \cdot \min ^{-1}\right)$. Hepatic glucose output (HGO) increased in Study I $\left(10.2 \pm 0.5\right.$ to $\left.13.1 \pm 0.9 \mu \mathrm{mol} \cdot \mathrm{kg}^{-1} \cdot \mathrm{min}^{-1}, P<0.01\right)$ and Study II $\left(11.17 \pm 0.67\right.$ to $13.33 \pm 0.83 \mu \mathrm{mol} \cdot \mathrm{kg}^{-1} \cdot \mathrm{min}^{-1}$, $P<0.01)$, and gluconeogenesis decreased $(57.6 \pm 6.4$ to $33.4 \pm 4.9 \mu \mathrm{mol} / \mathrm{min}, P<0.01$ ), indicating an increase in glycogenolysis. The increase in glycogenolysis was only partly compensated by an increase in glucose cycle activity (2.2 \pm 0.2 to $\left.3.4 \pm 0.4 \mu \mathrm{mol} \cdot \mathrm{kg}^{-1} \cdot \mathrm{min}^{-1}, P<0.01\right)$ and the fall in gluconeogenesis, thus resulting in increased HGO. The suppression of gluconeogenesis despite increased lactate and alanine (glycerol was decreased) was associated with decreased free fatty acid (FFA) oxidation and negligible FFA enhanced gluconeogenesis. These studies suggest that increased liver glycogen stores alone can overwhelm normal intrahepatic mechanisms regulating carbohydrate metabolism resulting in increased HGO in nondiabetic man. $(J$. Clin. Invest. 1995. 96:1967-1972.) Key words: glycogen • glucose-6-phosphatase • gluconeogenesis • insulin • futile cycle
\end{abstract}

\section{Introduction}

Two observations suggest that hepatic glycogen stores may play a role in the increased hepatic glucose output $(\mathrm{HGO})^{1}$ observed in patients with non-insulin-dependent diabetes mellitus

Address correspondence to John N. Clore, MD, Division of Endocrinology and Metabolism, Medical College of Virginia/Virginia Commonwealth University, Box 980111, Richmond, VA 23298-0111. Phone: 804-828-9695; FAX: 804-828-8100; E-mail: CLORE@GEMS.VCU.EDU

Received for publication 14 February 1995 and accepted in revised form 29 June 1995.

1. Abbreviations used in this paper: FFA, free fatty acids; HGO, hepatic glucose output; NIDDM, non-insulin-dependent diabetes mellitus

J. Clin. Invest.

(C) The American Society for Clinical Investigation, Inc.

0021-9738/95/10/1967/06\$2.00

Volume 96, October 1995, 1967-1972
(NIDDM). First, we (1) and others $(2,3)$ have shown that liver glycogen stores, presumably formed by the indirect (gluconeogenic) pathway, are actually well preserved in the diabetic state. Second, the beneficial effect of caloric restriction on HGO in patients with NIDDM occurs despite continued gluconeogenesis (4), suggesting a reduction in glycogenolysis as the cause of the improvement. Although rates of gluconeogenesis are increased in patients with $\operatorname{NIDDM}(5,6)$, this alone should not be sufficient to increase HGO since an increase in gluconeogenesis is associated with a compensatory fall in glycogenolysis in nondiabetic subjects (7-9). Therefore, we have proposed that continued glycogen release as well as increased gluconeogenesis is responsible for the increase in HGO in diabetic patients.

To examine the effect of increased glycogen stores on glucokinetics and hepatic metabolism, we have performed a series of overfeeding studies projected to greatly enlarge hepatic glycogen stores in normal volunteers (10). Under these conditions, we have demonstrated an increase in HGO and glucose cycling and suppression of gluconeogenesis. These studies indicating a loss of normal intrahepatic mechanisms which reciprocally regulate gluconeogenesis and glycogenolysis when glycogen stores are greatly increased are consistent with an important contributory role of preserved glycogen stores in NIDDM where the autoregulatory mechanisms are already impaired.

\section{Methods}

15 normal volunteers (Table I) were enrolled for the metabolic studies. Body composition was determined by skinfold measurements (11) and bioimpedance performed after an overnight fast (12). Six of the subjects participated in studies examining the effect of overfeeding on glucose cycle activity (study I) and the remaining nine subjects were enrolled in studies to determine the effect of overfeeding on FFA-stimulated gluconeogenesis ( study II). All of the subjects were in good health with stable body weights at the time of the studies. None had a family history of diabetes mellitus. Women were studied during the early follicular phase of their menstrual cycles and none of the women were taking exogenous estrogens or progestins. The studies were approved by the Committee for the Conduct of Human Research at the Medical College of Virginia/Virginia Commonwealth University and informed consent was obtained from each subject prior to enrollment in the protocols.

\section{Study diets}

Before admission to the General Clinical Research Center, each subject was interviewed by a nutritionist to determine usual caloric intake and composition. The diet was then individually designed to increase caloric intake by $\sim 4.0 \mathrm{~mJ}(1,000 \mathrm{kcal})$ daily as previously described $(10,13)$. Mean baseline intake was $7.5 \pm 0.5 \mathrm{MJ}$ and increased to $23.5 \pm 0.6 \mathrm{MJ}$ on the last day of the study. Composition of the diet was $67 \%$ carbohydrate, $22 \%$ fat and $11 \%$ protein.

\section{Study design}

All subjects were admitted to the Clinical Research Center at the Medical College of Virginia for the five-day studies. Metabolic assessments were performed supine after an overnight $(10 \mathrm{~h}$ ) fast on day 1 (before overfeeding) and day 5 (after overfeeding). Subjects received only water or ice chips during the two metabolic assessment periods. Vigorous 
Table I. Demographic Data on Subjects Enrolled in Overfeeding Studies

\begin{tabular}{ccccccc}
\hline Study & $n(\mathrm{M} / \mathrm{F})$ & Age & Ht $(\mathrm{m})$ & Wt $(\mathrm{kg})$ & $\begin{array}{c}\mathrm{BMI} \\
\left(\mathrm{kg} / \mathrm{m}^{2}\right)\end{array}$ & $\begin{array}{c}\text { Percent } \\
\text { body fat }\end{array}$ \\
\hline I & $6(6 / 0)$ & $23.8 \pm 0.5$ & $1.80 \pm 0.02$ & $75.7 \pm 4.1$ & $23.2 \pm 0.9$ & $18.9 \pm 1.6$ \\
II & $9(5 / 4)$ & $23.9 \pm 0.5$ & $1.80 \pm 0.03$ & $70.6 \pm 4.3$ & $21.8 \pm 0.7$ & $18.9 \pm 1.9$
\end{tabular}

activity was not permitted during the study period. At $0700 \mathrm{~h}$, an intravenous catheter was placed into a forearm vein for the infusion of isotopes, Intralipid and heparin, or saline according to study design. Another catheter was placed retrograde in a hand vein and the hand was placed in a plexiglass box heated to $60^{\circ} \mathrm{C}$ in order to obtain arterialized venous blood samples for the measurement of radioactivity, intermediary metabolites and glucoregulatory hormones. Both catheters were kept patent with an infusion of normal saline.

Study I. Subjects received a primed (100-fold), continuous infusion of $\left[2-{ }^{3} \mathrm{H}\right]$ glucose $(0.25 \mu \mathrm{Ci} / \mathrm{min})$ and $\left[6-{ }^{14} \mathrm{C}\right]$ glucose $(0.13 \mu \mathrm{Ci} / \mathrm{min})$ for $2 \mathrm{~h}$ on each study day, and sequential blood samples were obtained after achieving isotopic steady state. (Preliminary studies in which the isotope infusion was extended to 5 hours confirmed isotopic steady state after $2 \mathrm{~h}$ of infusion on each of the two study days; results shown in Table II). Indirect calorimetry was performed on the two study days using a Sensormedics 2000 metabolic cart (Anaheim, CA) equipped with a plastic canopy in order to measure oxygen consumption $\left(\mathrm{VO}_{2}\right.$ liters/min) and carbon dioxide production $\left(\mathrm{VCO}_{2}\right.$, liters $\left./ \mathrm{min}\right)$.

Study II. Subjects in Study II received a primed (100-fold), continuous infusion of $\left[3-{ }^{3} \mathrm{H}\right]$ glucose $(0.25 \mu \mathrm{Ci} / \mathrm{min})$ and $\left[\mathrm{U}-{ }^{14} \mathrm{C}\right]$ alanine $(0.13 \mu \mathrm{Ci} / \mathrm{min})$ for $4 \mathrm{~h}$ on each of the two study days. Blood samples were obtained after 2 hours of infusion and indirect calorimetry was performed as described above. The specific activity of $\left[{ }^{14} \mathrm{C}\right]$ glucose did not change during the final $30 \mathrm{~min}$ of the baseline period on either study day, suggesting that isotopic steady state had been achieved. Thereafter an infusion of heparin $\left(90 \mathrm{mU} \cdot \mathrm{kg}^{-1} \cdot \mathrm{min}^{-1}\right)$ and $10 \%$ Intralipid (Baxter Travenol, Deerfield, IL) was administered for an additional $2 \mathrm{~h}$ and sequential blood samples were obtained and indirect calorimetry was repeated. To match the levels of free fatty acids achieved during Intralipid infusion on day 1 , the rate of Intralipid infusion was increased from 1.0 to $1.5 \mathrm{cc} / \mathrm{min}$ on day 5 (see Results). Urine samples were collected after the basal period and after infusion of Intralipid and heparin (study II) for measurement of urinary nitrogen.

\section{Sample analyses}

Arterialized venous blood samples were obtained at selected time intervals and placed immediately into ice-cold fluoridated tubes for determination of specific activity of glucose and alanine and measurement of plasma hormones and intermediary metabolites. Plasma glucose was measured by the glucose oxidase method (Beckman, Fullerton CA) Plasma insulin (14), C-peptide (15), and glucagon (16) were determined with double antibody radioimmunoassays. Plasma free fatty acids (FFA) was determined by enzymatic methods (17). Blood samples for measurement of intermediary metabolites were immediately deproteinized with ice cold $3 \mathrm{M}$ perchloric acid. The supernatant was neutralized with $3 \mathrm{M} \mathrm{KOH}$ and the resulting supernatant assayed for L-lactate, alanine, $\beta$-hydroxybutyrate and acetoacetate (18), citrate (19) and glycerol (20) with microfluorometric assays. Urinary nitrogen was determined by the Kjeldahl method.

\section{Isotopic analyses}

Aliquots of plasma for the determination of glucose specific activity were deproteinized with $\mathrm{Ba}(\mathrm{OH})_{2}$ and $\mathrm{ZnSO}_{4}(21)$ and the supernatant was chromatographed over sequential anion and cation exchange resins as previously described $(8)$. For studies in which $\left[6-{ }^{14} \mathrm{C}\right]$ glucose was infused, the neutral fraction was air-dried and was resuspended in 133 $\mathrm{mM}$ phosphate buffer ( $\mathrm{pH} 7.4$ ) and was divided into two equal fractions.
Table II. Mean Glucose Radioactivity (DPM/ml) during Extended $(5 \mathrm{~h})$ Infusion of $\left[2-{ }^{3} \mathrm{H}\right]$ Glucose in Two Normal Male Volunteers before (Day 1) and after (Day 5) Overfeeding

\begin{tabular}{lcccccc}
\hline Study day & $2 \mathrm{H}$ & $3 \mathrm{H}$ & $3.5 \mathrm{H}$ & $4 \mathrm{H}$ & $4.5 \mathrm{H}$ & $5 \mathrm{H}$ \\
\hline Day 1 & 2398 & 2415 & 2399 & 2337 & 2368 & 2296 \\
Day 5 & 2424 & 2462 & 2267 & 2238 & 2236 & 2220 \\
\hline
\end{tabular}

The first fraction was placed in scintillation fluid (Budget-Solv; RPI, Mount Prospect IL) and was counted in a liquid scintillation counter (Beckman LS1700) equipped with the appropriate software for dual label counting and quench correction. The second fraction was used for the determination of label randomization from the six-position of glucose to the 1-position by decarboxylation of the $\left[1-{ }^{14} \mathrm{C}\right]$ glucose $(8)$. Greater than $94 \%$ efficiency of decarboxylation was confirmed with $\left[1-{ }^{14} \mathrm{C}\right]$ glucose under identical conditions. For studies in which [3${ }^{3} \mathrm{H}$ ] glucose and $\left[\mathrm{U}-{ }^{14} \mathrm{C}\right.$ ] alanine were used, the deproteininzed plasma was chromatographed as described above to elute the neutral (glucose) fraction, and the alanine and lactate were then eluted separately from the exchange resins. All fractions were then placed in scintillation fluid and counted.

\section{Calculations}

Rates of glucose appearance ( $\mathrm{Ra})$ and disappearance $(\mathrm{Rd})$ as determined by the respective glucose tracers $\left(\left[2-{ }^{3} \mathrm{H}\right],\left[3-{ }^{3} \mathrm{H}\right]\right.$ and $\left[6-{ }^{14} \mathrm{C}\right]$ glucose $)$ were calculated from the equations of Steele as modified by DeBodo (22) using a glucose pool fraction of 0.65 (23). Specific activity was calculated as the ratio of plasma radioactivity (corrected for recovery over the ion exchange columns) and plasma substrate concentrations. Correction of the $\left[{ }^{14} \mathrm{C}\right]$ glucose counts for the randomization of label was accomplished by multiplying the counts in $\mathrm{C}-1$ of glucose by a factor of 4 and subtracting this value from the uncorrected $\left[{ }^{14} \mathrm{C}\right]$ glucose counts (8). Glucose cycle is defined as the $\mathrm{Ra}$ of $\left[2-{ }^{3} \mathrm{H}\right]$ glucose minus the $\mathrm{Ra}$ of $\left[6-{ }^{14} \mathrm{C}\right]$ glucose. Cori cycle activity is defined as the difference between the corrected and uncorrected $\left[{ }^{14} \mathrm{C}\right]$ glucose turnover. For the determination of gluconeogenesis, the dual isotope technique of Chiasson et al (24) was used. Alanine gluconeogenesis was also calculated as the percent of alanine incorporated into glucose according to the formula:

\section{$\%$ glucose from alanine}

\section{$=\left(\left[{ }^{14} \mathrm{C}\right]\right.$ glucose $\left.\mathrm{SA}\right) \times 100 /\left(\left[{ }^{14} \mathrm{C}\right]\right.$ alanine $\left.\mathrm{SA}\right) \times 2$.}

Calculation of carbohydrate and lipid oxidation was performed using the equations of Frayn using the non-protein respiratory quotient (25). Protein oxidation was estimated as $6.25 \times$ urinary $\mathrm{N}$ excretion $(\mathrm{gm} /$ $\min$ ). Non-oxidative glucose disposal was calculated as the difference between the rates of glucose disposal measured isotopically and carbohydrate oxidation measured by indirect calorimetry.

Statistical analysis between treatments was performed with analysis of variance and within treatments using repeated measures analysis of variance and a multiple comparison test. Statistical significance was assumed when $P<0.05$. Results are expressed as means \pm SE.

\section{Results}

Effect of overfeeding on intermediary metabolism. The effects of overfeeding on basal energy expenditure, substrate metabolism, and body weight for all subjects $(n=15)$ are shown in Table III. Mean non-protein respiratory quotient (NPRQ) increased from $0.78 \pm 0.02$ to $0.94 \pm 0.01$ in the 15 study subjects $(P<0.001)$. In four of the subjects, the NPRQ exceeded 1.00 after overfeeding, indicating net lipogenesis. Overfeeding also 
Table III. The Effect of Overfeeding on Nonprotein Respiratory Quotient (NPRQ), Resting Energy Expenditure (kJ/min), Substrate Oxidation (grams/min), and Body Weight in 15 Nondiabetic Volunteers

\begin{tabular}{ccccccc}
\hline Study day & NPRQ & REE & \multicolumn{1}{c}{ CHO $_{\text {ox }}$} & \multicolumn{1}{c}{ Lipid $_{\text {ox }}$} & Protein $_{\text {ox }}$ & Body wt (kg) \\
\hline 1 & $0.78 \pm 0.02$ & $4.98 \pm 0.20$ & $0.074 \pm 0.023$ & $0.073 \pm 0.009$ & $0.045 \pm 0.004$ & $73.4 \pm 5.5$ \\
5 & $0.94 \pm 0.01^{*}$ & $5.44 \pm 0.24 *$ & $0.261 \pm 0.023^{*}$ & $0.022 \pm 0.006 *$ & $0.022 \pm 0.003^{*}$ & $74.5 \pm 5.7$ \\
\hline
\end{tabular}

Results are shown as mean \pm SEM. $* P<0.0001$ compared with day 1 values.

resulted in significant increases in resting energy expenditure and carbohydrate oxidation and decreases in lipid and protein oxidation. Levels of glucoregulatory hormones and intermediary metabolites before and after overfeeding are shown in Table IV. Significant increases in plasma glucose, insulin, and Cpeptide were observed in all of the subjects after overfeeding. Plasma lactate and alanine levels also increased significantly during the overfeeding period and plasma FFA, glycerol, citrate and ketones fell. These changes are consistent with an increase in carbohydrate oxidation and decrease in lipolysis and lipid oxidation. No significant change in body weight was observed during short term overfeeding.

Study I. In the six subjects participating in Study I, fasting plasma glucose $(5.15 \pm 0.14$ to $5.46 \pm 0.09 \mathrm{mM}, P<0.001)$, insulin $(36.1 \pm 6.3$ to $65.6 \pm 20.3 \mathrm{pmol} / \mathrm{liter}, P<0.01)$ and $\mathrm{C}$ peptide $(0.40 \pm 0.07$ to $0.63 \pm 0.20 \mathrm{nmol} /$ liter, $P<0.01)$ levels rose during the overfeeding study. Rates of total glucose appearance $\left(\mathrm{Ra}_{[2-3 \mathrm{H}]} ; 12.5 \pm 0.6\right.$ to $16.5 \pm 0.8 \mu \mathrm{mol} \cdot \mathrm{kg}^{-1} \cdot \mathrm{min}^{-1}, P$ $<0.01$ ) and $\mathrm{Ra}_{14 \mathrm{C}}$ (after correction for recycling) (10.2 \pm 0.5 to $\left.13.1 \pm 0.9 \mu \mathrm{mol} \cdot \mathrm{kg}^{-1} \cdot \mathrm{min}^{-1}, P<0.01\right)$ increased significantly after overfeeding (Fig. 1). Glucose cycling (the difference between $\mathrm{Ra}_{2}{ }^{3} \mathrm{H}$ and $\mathrm{Ra}^{14}{ }_{\mathrm{C}}$ ) also increased significantly during the 5-d overfeeding study from $2.2 \pm 0.2$ to $3.4 \pm 0.4 \mu \mathrm{mol} \cdot \mathrm{kg}^{-1}$. $\min ^{-1}(P<0.01$, Fig. 1$)$. The effect of overfeeding on Cori cycle activity (the conversion of $\left[6-{ }^{14} \mathrm{C}\right]$ glucose to $\left[1-{ }^{14} \mathrm{C}\right]-$ glucose) was more variable although there was a trend toward a reduction $\left(1.25 \pm 0.32\right.$ to $1.12 \pm 0.30 \mu \mathrm{mol} \cdot \mathrm{kg}^{-1} \cdot \mathrm{min}^{-1}$, NS $)$. Overall carbohydrate oxidation increased from $5.49 \pm 1.70$ to $18.44 \pm 2.76 \mu \mathrm{mol} \cdot \mathrm{kg}^{-1} \cdot \mathrm{min}^{-1}$ in the six subjects who partici-

Table IV. Glucoregulatory Hormones and Intermediary Metabolites after an Overnight (10 h) Fast before (Day 1) and after (Day 5) Overfeeding in Nondiabetic Men $(n=11)$ and Women $(n=4)$

\begin{tabular}{lcc}
\hline & Day 1 & Day 5 \\
\hline Glucose $(\mathrm{mmol} / \mathrm{liter})$ & $4.97 \pm 0.10$ & $5.31 \pm 0.07^{*}$ \\
Insulin $(\mathrm{pmol} / \mathrm{liter})$ & $18.8 \pm 1.5$ & $46.6 \pm 10.0^{\ddagger}$ \\
C-peptide $(\mathrm{nmol} / \mathrm{liter})$ & $0.34 \pm 0.03$ & $0.51 \pm 0.07^{\ddagger}$ \\
Glucagon $(\mathrm{pg} / \mathrm{ml})$ & $120.9 \pm 8.1$ & $127.2 \pm 7.2$ \\
FFA $(\mu \mathrm{mol} / \mathrm{liter})$ & $524.1 \pm 58.6$ & $195.7 \pm 27.0^{\S}$ \\
Glycerol $(\mu \mathrm{mol} / \mathrm{liter})$ & $82.0 \pm 7.2$ & $55.6 \pm 8.5^{\ddagger}$ \\
Lactate $(\mu \mathrm{mol} / \mathrm{liter})$ & $1096.5 \pm 96.1$ & $1490.1 \pm 95.1^{\S}$ \\
Alanine $(\mu \mathrm{mol} / \mathrm{liter})$ & $338.8 \pm 29.8$ & $477.4 \pm 31.9^{\S}$ \\
$\beta$-hydroxybutyrate $(\mu \mathrm{mol} / / \mathrm{liter})$ & $120.0 \pm 21.7$ & $31.2 \pm 2.9^{\S}$ \\
Acetoacetate $(\mu \mathrm{mol} / \mathrm{liter})$ & $74.1 \pm 16.9$ & $27.7 \pm 11.5^{\S}$ \\
Citrate $(\mu \mathrm{mol} / \mathrm{liter})$ & $90.9 \pm 4.9$ & $71.2 \pm 5.3^{\S}$ \\
& &
\end{tabular}

${ }^{*} P<0.05 ;{ }^{\ddagger} P<0.01 ;{ }^{\S} P<0.001$. pated in study I. However, the rate of glucose disposal measured isotopically, which in the basal state is equal to the rate of glucose appearance, did not increase to the same extent. As a result, non-oxidative glucose disposal (Rd-CHOox) fell in all subjects $\left(7.84 \pm 1.82\right.$ to $-0.95 \pm 2.30 \mu \mathrm{mol} \cdot \mathrm{kg}^{-1} \cdot \mathrm{min}^{-1}, P$ $<0.01)$. The negative values have previously been attributed to increased glycogenolysis (26).

Study II. Baseline fasting plasma glucose and insulin levels in subjects in Study II were not significantly different from those in Study I, and rose similarly after 4 days of overfeeding. Plasma glucose increased from $4.84 \pm 0.15$ to $5.21 \pm 0.11 \mathrm{mM}$ during the overfeeding study in association with an increase in plasma insulin $(19.9 \pm 1.6$ to $47.5 \pm 8.7 \mathrm{pmol} / \mathrm{liter}, P<0.01)$ and C-peptide $(0.32 \pm 0.04$ to $0.45 \pm 0.04 \mathrm{nmol} /$ liter, $P<0.01)$. Glucose appearance measured by $\left[3-{ }^{3} \mathrm{H}\right]$ glucose infusion increased from $11.17 \pm 0.67$ to $13.33 \pm 0.83 \mu \mathrm{mol} \cdot \mathrm{kg}^{-1} \cdot \mathrm{min}^{-1}(P$ $<0.01)$. Overfeeding was also associated with a significant increase in alanine appearance $\left(5.4 \pm 0.6\right.$ to $7.6 \pm 0.6 \mu \mathrm{mol} \cdot \mathrm{kg}^{-1}$ $\left.\cdot \min ^{-1}, P<0.01\right)$. However, baseline rates of alanine gluconeogenesis fell by $42 \%$ from $57.6 \pm 6.4$ to $33.4 \pm 4.9 \mu \mathrm{mol} / \mathrm{min}$ $(P<0.01)$. When alanine gluconeogenesis is expressed as a percent of alanine turnover, overfeeding reduced the percentage from $3.85 \pm 0.51$ to $2.14 \pm 0.34 \%(P<0.01)$.

To determine if the hepatic response to increased FFA availability is altered by overfeeding, an infusion of Intralipid and heparin was administered for two hours on each of the two study days and rates of $\mathrm{HGO}$ and alanine gluconeogenesis were measured. No changes in plasma glucose or insulin were observed during lipid infusion on either study day. The profiles of intermediary metabolites during lipid infusion are shown in Fig. 2. Plasma FFA levels rose during lipid infusion from $579.2 \pm 101.5$ to $1111.8 \pm 222.8 \mu \mathrm{mol} /$ liter on Day 1 , and from $225.3 \pm 54.1$ to $1065.9 \pm 297.4 \mu \mathrm{mol} /$ liter on Day 5. Although baseline plasma FFA concentrations were significantly lower after overfeeding, levels achieved during the final $30 \mathrm{~min}$ of Intralipid infusion (infusion rate increased in the overfeeding arm of study) were not significantly different. Lipid oxidation measured by indirect calorimetry increased from $1.26 \pm 0.28$ to $1.58 \pm 0.19 \mu \mathrm{mol} \cdot \mathrm{kg}^{-1} \cdot \mathrm{min}^{-1}$ on day $1(P<0.01)$ and from $0.34 \pm 0.10$ to $0.64 \pm 0.22 \mu \mathrm{mol} \cdot \mathrm{kg}^{-1} \cdot \min ^{-1}(P<0.01)$ on day 5 during lipid infusion. However, the hepatic response to lipid infusion was blunted by overfeeding. As shown in Fig. 2, plasma ketones $(\beta-\mathrm{OHB}+$ acetoacetate $)$ increased during the lipid infusion on Day $1(203.8 \pm 61.4$ to $439.0 \pm 111.9 \mu \mathrm{mol} /$ liter, $P<0.001$ ). In contrast, plasma ketones were significantly lower after overfeeding, and did not change during lipid infusion on day 5. Rates of glucose appearance did not increase during lipid administration on either study day (Fig. 3). However, clear differences in the gluconeogenic response to lipid infusion were observed on the two study days. Alanine gluconeogenesis increased significantly from baseline during lipid administration 


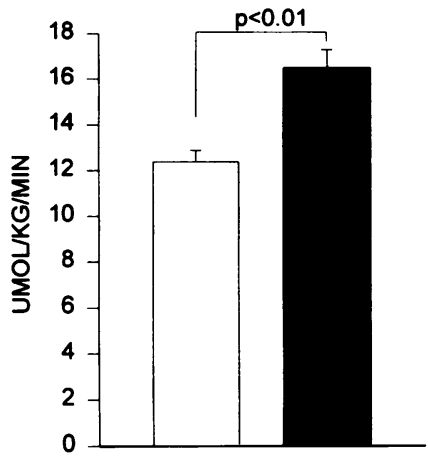

$\mathrm{Ra}^{3} \mathrm{H}$

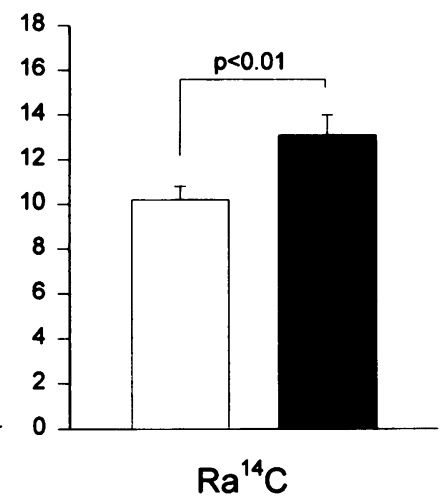

$\operatorname{Ra}{ }^{14} \mathrm{C}$ on day $1(P<0.05)$, but did not increase during lipid administration on day 5 (Fig. 3 ).

\section{Discussion}

We have demonstrated an increase in hepatic glucose production after overfeeding in non-diabetic subjects. This increase
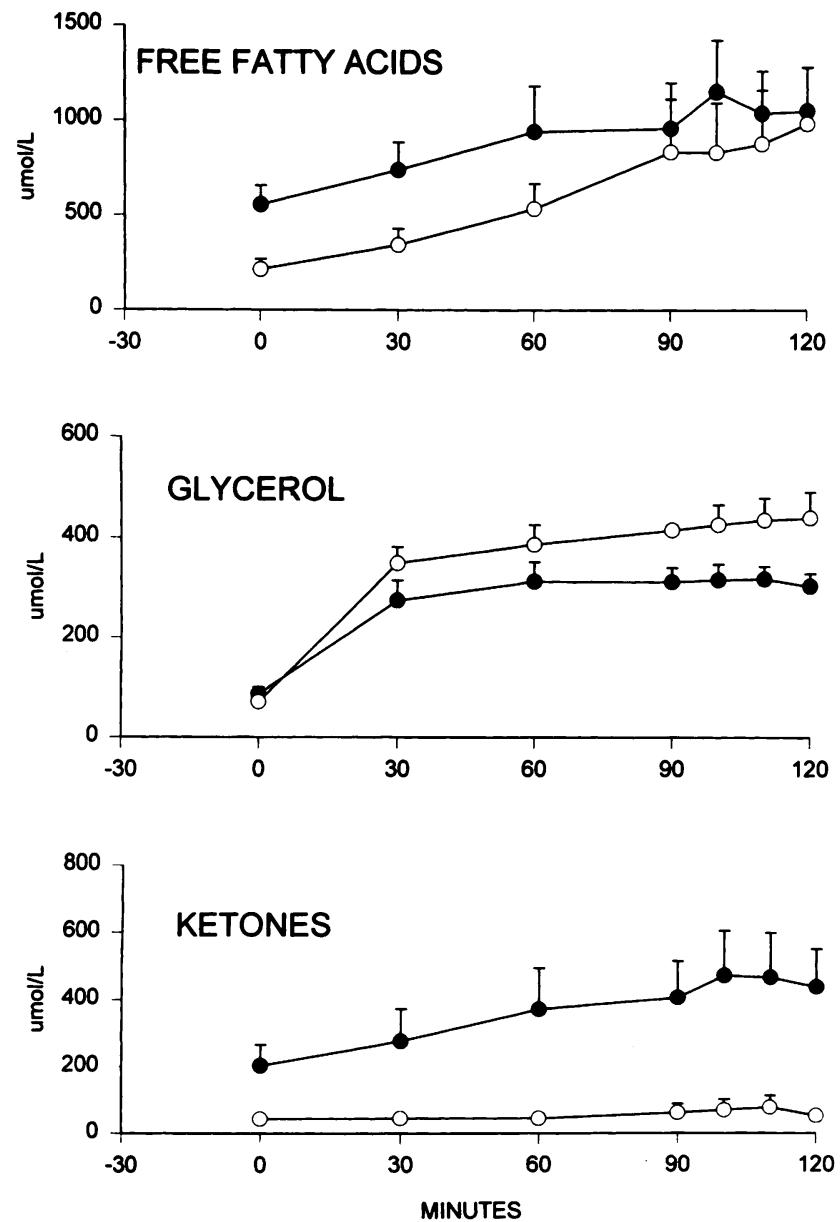

Figure 2. Plasma free fatty acids, glycerol and ketones ( $\beta$-hydroxybutyrate + acetoacetate) during a $10 \%$ Intralipid and heparin infusion in normal volunteers before $(\bullet)$ and after $(0)$ carbohydrate overfeeding. Results shown are mean \pm SEM, $n=9$.

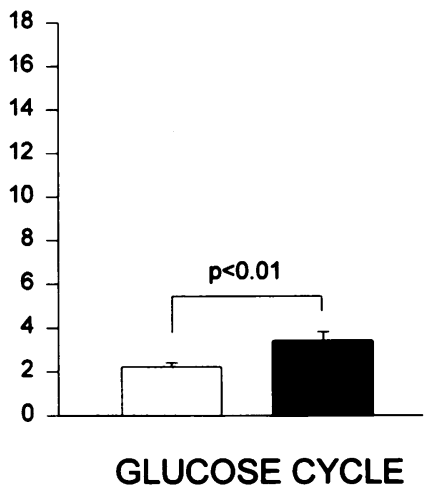

Figure 1. Rates of glucose appearance measured with $\left[2-{ }^{3} \mathrm{H}\right]$ glucose $\left(\mathrm{Ra}^{3} \mathrm{H}\right),\left[6-{ }^{14} \mathrm{C}\right]$ glucose $\left(\mathrm{Ra}^{14} \mathrm{C}\right)$ and glucose cycle activity before ( $\square$ ) and after ( $\square$ ) carbohydrate overfeeding in six normal volunteers. Results shown are mean \pm SEM.

occurred despite an increase in plasma insulin. In the postabsorptive state, HGO is derived from both gluconeogenesis and glycogenolysis which are tightly linked to maintain $\mathrm{HGO}$ at a level to meet peripheral glucose demands $(8)$. Numerous studies examining the effect of stimulation $(7,8)$ or inhibition (3) of gluconeogenesis on HGO in nondiabetic men and women have consistently demonstrated hepatic autoregulation. However, all of these studies have been performed after an overnight fast, when liver glycogen stores are considerably lower than
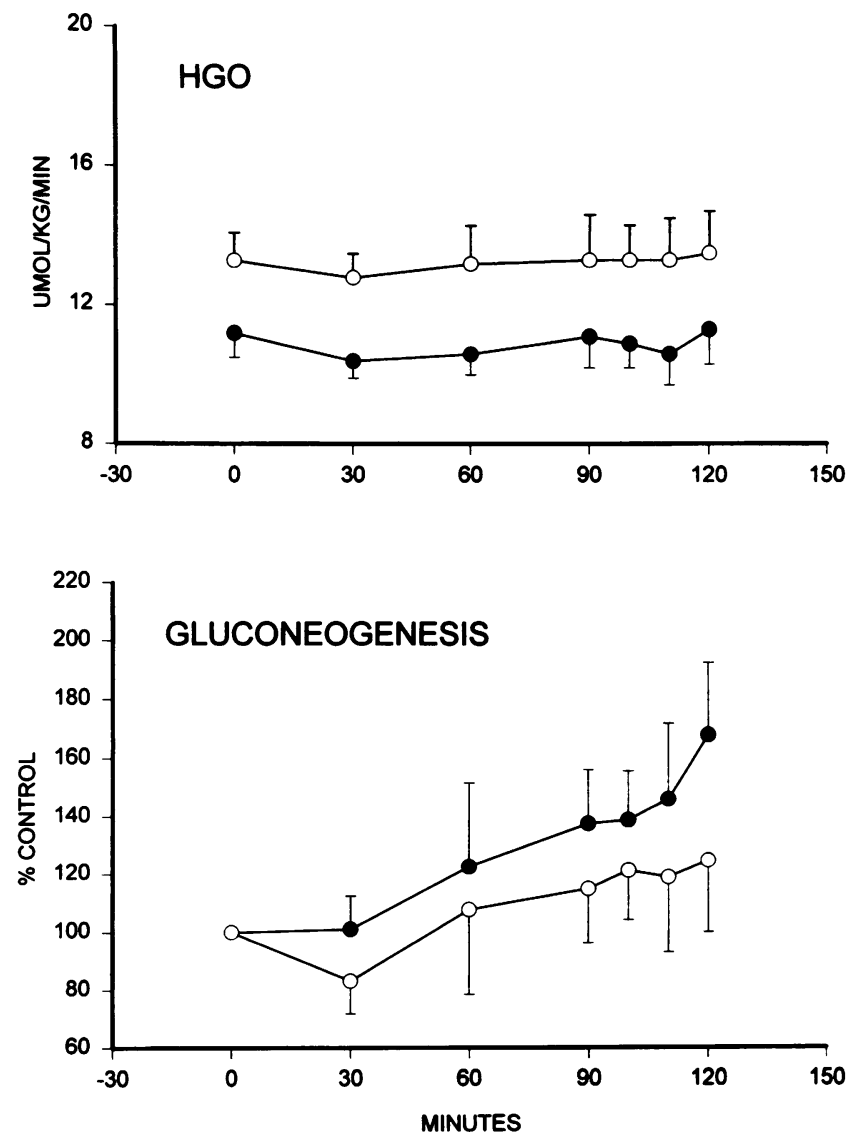

Figure 3. Rates of hepatic glucose output ( $H G O$, top panel) and alanine gluconeogenesis (bottom panel) during infusion of $10 \%$ Intralipid and heparin before $(\bullet)$ and after $(0)$ carbohydrate overfeeding. Results shown are mean \pm SEM, $n=9$. 
capacity (27). In contrast, the present studies examined HGO under conditions which would be expected to increase liver glycogen stores (10). Our data suggest that under these conditions, gluconeogenesis is suppressed and that glucose derived from glycogen is released in excess of metabolic needs, accounting for the increase in HGO.

In the present studies, HGO was measured by tracer techniques using infusions of either $\left[2-{ }^{3} \mathrm{H}\right]$ glucose, $\left[3-{ }^{3} \mathrm{H}\right]$ glucose or $\left[6-{ }^{14} \mathrm{C}\right]$ glucose. Results obtained from each of these isotopes demonstrate an increase in HGO with overfeeding. Some of the increase in glucose turnover in these studies is the result of increased futile cycle activity. Glucose cycle activity (the difference between $\mathrm{Ra}_{2}{ }^{3}$ and $\mathrm{Ra}^{14}{ }_{\mathrm{C}}$ ) increased by $>50 \%$ in our studies. The glucose cycle is defined by the phosphorylation and dephosphorylation of glucose and, in the postabsorptive state, increases when there is a net increase in flux through phosphorylation (glucokinase activity) compared with dephosphorylation (glucose-6-phosphatase activity) (28). In the present studies fasting plasma insulin and C-peptide levels were increased by overfeeding, and previous investigators have demonstrated postprandial hyperinsulinemia after overfeeding (13, 29) which would be expected to increase glucokinase activity as well as glucokinase gene expression (30). To the extent that the detritiation of $\left[2{ }^{3} \mathrm{H}\right]$ glucose may not be complete, our calculation of glucose cycling will be underestimated (31). However, it is unlikely that the percentage of incomplete detritiation would decrease after overfeeding to explain the observed increase in glucose cycle activity. With regard to glucose appearance as measured by $\left[3-{ }^{3} \mathrm{H}\right]$ glucose, an increase in the $\mathrm{F}$ $6-\mathrm{P} \leftrightarrow \mathrm{F}-1,6-\mathrm{P}_{2}$ cycle ( second futile cycle) or an increase in pentose pathway activity could explain some of the increase in glucose appearance observed with this tracer (31). Since carbohydrate overfeeding is associated with an increase in denovo lipogenesis (10), a process which requires pentose pathway activity for the production of NADPH, an increase in the pentose pathway is likely. On the other hand, the conditions of these studies should decrease the second futile cycle. The similarity in rates of glucose appearance using $\left[6-{ }^{14} \mathrm{C}\right]$ glucose and $\left[3-{ }^{3} \mathrm{H}\right]$ glucose (unpaired data) are consistent with minimal activity of the second futile cycle. Thus, despite increases in glucose cycle activity (which may have prevented HGO from increasing further) (28), our data are consistent with an increase in net glucose production by the liver.

It seems likely that liver glycogen stores were increased by overfeeding in our studies. Although liver glycogen stores were not measured in our subjects, Nilsson has shown increased liver glycogen stores in liver biopsies from nondiabetic subjects after ingestion of $300 \mathrm{gm} / \mathrm{d}$ carbohydrate for 1-5 d (32). During the present studies, carbohydrate intake began at $300 \mathrm{gm} / \mathrm{d}$ and increased to $900 \mathrm{gm} / \mathrm{d}$ by the fourth day of overfeeding. Using this protocol, whole body carbohydrate storage has been estimated to increase to $15 \mathrm{gm} / \mathrm{kg}$ total body weight (10). Assuming maximum muscle glycogen storage to be $2.4 \%$ (33) and muscle mass to be $40 \%$ of body weight, liver glycogen concentrations in our subjects may have exceeded $1000 \mu \mathrm{mol} / \mathrm{L}$, a value threefold greater than normal postabsorptive levels (32). However, continued storage of liver glycogen may have been attenuated by an increase in glycogen release which occurs with increasing glycogen content $(34,35)$. Since rates of gluconeogenesis decreased with overfeeding, increased glycogen release seems the likely source for the increase in HGO observed in our studies.
We have previously demonstrated an increase in glycogenolysis when gluconeogenesis was inhibited by ethanol administration in diabetic and nondiabetic individuals (4) which has been confirmed in animal studies (36). The conditions associated with overfeeding would also be expected to suppress gluconeogenesis. In the postabsorptive state, the liver derives the majority of its energy from the oxidation of FFA which also promotes gluconeogenesis (Fig. 3). After several days of overfeeding, hepatic FFA oxidation is replaced by carbohydrate oxidation, in part related to the expected reduction in FFA availability as well as insulin-mediated increases in fructose-2,6bisphosphate (37) and malonyl-CoA which inhibits FFA oxidation (38). The failure of Intralipid administration to increase gluconeogenesis or ketone production in our subjects on day 5 emphasizes the changes in hepatic metabolism which occurred after overfeeding (Fig. 2, Table IV).

Although our data demonstrate a qualitative fall in gluconeogenesis, we are not able to quantify the extent of the decrease in rates of gluconeogenesis with overfeeding because of isotopic dilution. Dilution occurs by exchange of ${ }^{14} \mathrm{C}$ and ${ }^{12} \mathrm{C}$ within the TCA cycle (39), and studies attempting to measure isotopic dilution after overfeeding are not available in the literature. However, the fall in urinary nitrogen excretion $(0.007 \pm 0.001$ to $0.003 \pm 0.001 \mathrm{gm} / \mathrm{min}$ ) after overfeeding is consistent with a decrease in gluconeogenesis (25). Thus, it seems likely that gluconeogenesis was suppressed and glycogenolysis increased by overfeeding. The increase in HGO observed in the present studies suggests that the production of G-6-P from glycogen provided increased substrate for G-6-Pase.

G-6-Pase catalyzes the final step in hepatic (and renal) glucose production from G-6-P derived from either gluconeogenesis or glycogenolysis. Enzyme activity is known to increase in insulin-deficient states and falls with insulin administration in streptozotocin animals (40). Whether mild hyperinsulinemia such as that produced by overfeeding suppresses G-6-Pase activity in non-diabetic man is not known. Rossetti and colleagues have recently shown that acute hyperinsulinemia leads to a modest $20-30 \%$ suppression of maximal G-6-Pase activity without altering $K_{\mathrm{m}}$ in diabetic and non-diabetic rats (41). Moreover, we have shown that chronic hyperinsulinemia suppresses G-6-Pase activity and G-6-Pase mRNA in rats (unpublished observations). However, even if $V_{\max }$ for G-6-Pase was suppressed by hyperinsulinemia in the present studies, a sufficient increase in substrate delivery might be expected to increase G-6-P phosphohydrolysis and HGO.

HGO is also increased in NIDDM. Recent studies have demonstrated that the increase in HGO is observed only when fasting plasma glucose levels exceed $7.8 \mathrm{mM}$, a level frequently used to define the diabetic state, but is not easily observed in patients with mild diabetes (42). Nevertheless, rates of glucose release by the liver are clearly inappropriate for the level of plasma glucose in all subjects with NIDDM. Although the activity or enzyme mass of G-6-Pase is not established in NIDDM, increased substrate for the enzyme, derived from either gluconeogenesis or glycogenolysis or both, must be present to explain an increase in HGO. The present studies suggest that an increase in glycogenolysis is sufficient to overwhelm hepatic autoregulatory mechanisms and increase HGO in nondiabetic subjects. In patients with NIDDM, increased gluconeogenesis is thought to be responsible for the increase in HGO $(5,6)$. However, an increase in gluconeogenesis and FFA oxidation does not increase HGO in nondiabetic man (8), suggesting that either 
impaired glycogen storage or impaired suppression of glycogenolysis must contribute to the impairment of hepatic autoregulation in NIDDM.

In conclusion, we have demonstrated an increase in HGO after $5 \mathrm{~d}$ of carbohydrate overfeeding in nondiabetic men and women despite an increase in insulin secretion and glucose cycle activity. The suppression of gluconeogenesis observed in these studies suggests that the increase in HGO is derived from enhanced release of liver glycogen. By analogy, we suggest a contributory role of the well-preserved hepatic glycogen stores to the increased $\mathrm{HGO}$ in diabetic man.

\section{Acknowledgments}

We would like to thank the staff of the General Clinical Research Center for their invaluable assistance in the performance of these studies. We would like to thank Ms. Martha Massie and Ms. Colleen Tansey in particular for their help in the dietary regimens.

Funds for these studies were provided by National Institutes of Health grants R29-DK43013 and MO1-RR00065 (GCRC).

\section{References}

1. Clore, J. N., E. P. Post, D. J. Bailey, J. E. Nestler, and W. G. Blackard. 1992. Evidence for increased liver glycogen in patients with non-insulin dependent diabetes mellitus after a three-day fast. J. Clin. Endocrinol. Metab. 74:660-666.

2. Puhakainen, I., and H. Yki-Jarvinen. 1993. Inhibition of lipolysis decreases lipid oxidation and gluconeogenesis from lactate but not fasting hyperglycemia or total hepatiuc glucose production in NIDDM. Diabetes. 42:1694-1699.

3. Puhakainen, I., V. A. Koivisto, and H. Yki-Jarvinen. 1991. No reduction in total hepatic glucose output by inhibition of gluconeogenesis with ethanol in NIDDM patients. Diabetes. 40:1319-1327.

4. Clore, J. N., and W. G. Blackard. 1994. Suppression of gluconeogenesis after a 3-day fast does not deplete liver glycogen in patients with NIDDM. Diabetes. 43:256-262.

5. Consoli, A., N. Nurjhan, F. Capani, and J. Gerich. 1989. Predominant role of gluconeogenesis in increased hepatic glucose production in NIDDM. Diabetes. 38:550-557.

6. Magnusson, I., D. L. Rothman, L. D. Katz, R. G. Shulman, and G. I. Shulman. 1992. Increased rate of gluconeogenesis in type II diabetes mellitus. A 13C nuclear magnetic resonance study. J. Clin. Invest. 90:1323-1327.

7. Jenssen, T., N. Nurjhan, A. Consoli, and J. E. Gerich. 1990. Failure of substrate-induced gluconeogenesis to increase overall glucose appearance in normal humans. J. Clin. Invest. 86:489-497.

8. Clore, J. N., P. S. Glickman, J. E. Nestler, and W. G. Blackard. 1991. In vivo evidence for hepatic autoregulation during FFA-stimulated gluconeogenesis in normal humans. Am. J. Physiol. 261:E425-429.

9. Jahoor, F., E. J. Peters, and R. R. Wolfe. 1990. The relationship between gluconeogenic substrate supply and glucose production in humans. Am. J. Physiol. 258:E288-96.

10. Acheson, K. J., Y. Schutz, T. Bessard, K. Anantharaman, J. Flatt, and E Jequier. 1988. Glycogen storage capacity and de novo lipogenesis during massive carbohydrate overfeeding in man. Am. J. Clin. Nutr. 48:240-247.

11. Durnin, J. V. G. A., and J. Womersley. 1974. Body fat assessed from total body density and its estimation from skinfold thickness: measurements on 48 men and women aged 17 to 72 years. Br. J. Nutr. 32:77-97.

12. Kushner, R. F. 1992. Bioelectrical impedance analysis: a review of principles and applications. J. Am. Coll. Nutr. 11:199-209.

13. Welle, S. L., T. B. Seaton, and R. G. Campbell. 1986. Some metabolic effects of overeating in man. Am. J. Clin. Nutr. 44:718-724.

14. Morgan, C. R., and A. Lazarow. 1963. Immunoassay of insulin:two antibody system:plasma insulin levels of normal, subdiabetic and diabetic rats. Diabe tes. 12:115-126.

15. Kumar, M. S., O. P. Schumacher, and S. D. Deodhar. 1980. Measurement of serum C-peptide immunoreactivity by radioimmunoassay in insulin-dependent diabetics. Am. J. Clin. Path 74:78-82.

16. Aquilar-Parada, E., A. M. Eisentraut, and R. H. Unger. 1969. Pancreatic glucagon secretion in normal and diabetic subjects. Am. J. Med. Sci. 257:415419.

17. Miles, J., R. Glasscock, J. Aikens, J. Gerich, and M. Haymond. 1983. A microfluorometric method for the determination of free fatty acids in plasma. $J$. Lipid Res. 24:96-99.

18. Maughn, R. J. 1982. A simple, rapid method for the determination of glucose, lactate, pyruvate, alanine, 3-hydroxybutyrate and acetoacetate on a single 201 blood sample. Clin. Chim. Acta. 122:231-240.

19. Nielsen, T. T. 1976. A method for enzymatic determination of citrate in serum and urine. Scand. J. Clin. Lab. Invest. 36:513-519.

20. Wieland, O. 1974. Enzymatic analysis of glycerol. In Methods of Enzymatic Analysis. H. U. Bergmeyer, editor. Academic, New York. 1404-1409.

21. Somogyi, M. 1945. Determination of blood sugar. J. Biol. Chem. 160:6973.

22. DeBodo, R. C., R. Steele, N. Altszuler, A. Dunn, and J S. Bishop. 1963. On the hormonal regulation of carbohydrate metabolism: studies with ${ }^{14} \mathrm{C}$-glucose. Recent Prog. Horm. Res. 19:445-488.

23. Cowan, J. S., and G. Hetenyi. 1971. Glucoregulatory responses in normal and diabetic dogs recorded by a new tracer method. Metabolism. 20:360-372.

24. Chiasson, J. L., J. Liljenquist, W. W. Lacy, A. Jennings, and A. D Cherrington. 1977. Gluconeogenesis: methodologic approaches in vivo. Fed Proc. 36:229-235.

25. Frayn, K. N. 1983. Calculation of substrate oxidation rates in vivo from gaseous exchange. Am. J. Physiol. 55:628-634.

26. Ferrannini, E. 1988. The theoretical bases of indirect calorimetry: a review Metabolism. 37:287-301

27. Rothman, D. L., I. Magnusson, L. D. Katz, R. G. Shulman, and G. I. Shulman. 1991. Quantitation of hepatic glycogenolysis and gluconeogenesis in fasting humans with 13C NMR. Science (Wash. DC). 254:573-576.

28. Efendic, S., S. Karlander, and M. Vranic. 1988. Mild type II diabetes markedly increases glucose cycling in the postabsorptive state and during glucose infusion irrespective of obesity. J. Clin. Invest. 81:1953-1961.

29. Mott, D. M., S. Lillioja, and C. Bogardus. 1986. Overnutrition induced decrease in insulin action for glucose storage: in vivo and in vitro in man. Metabolism. 35:160-165.

30. Iynedjian, P. B. 1993. Mammalian glucokinase and its gene. Biochem. J. 293:1-13.

31. Landau, B. R. 1993. Measuring glucose and fructose-6-phosphate cycling in liver in vivo. Metabolism. 42:457-462.

32. Nilsson, L. H., and E. Hultman. 1973. Liver glycogen in man-the effect of total starvation or a carbohydrate-poor diet followed by carbohydrate refeeding. Scand. J. Clin. Lab. Invest. 32:325-330.

33. Bjorntorp, P., and L. Sjostrom. 1978. Carbohydrate storage in man: speculations and some quantitative considerations. Metabolism. 27:1853-1865.

34. David, M., W. A. Petit, M. R. Laughlin, R. G. Shulman, J. E. King, and E. J. Barrett. 1990. Simultaneous synthesis and degradation of rat liver glycogen. An in vivo nuclear magnetic resonance spectroscopic study. J. Clin. Invest 86:612-617.

35. Magnusson, I., D. L. Rothman, B. Jucker, G. W. Cline, R. G. Shulman, and G. I. Shulman. 1994. Liver glycogen turnover in fed and fasted humans. Am. J. Physiol. 266:E796-803.

36. Kubota, M., A. Virkamaki, and H. Yki-Jarvinen. 1992. Ethanol stimulates glycogenolysis in livers from fed rats. Proc. Soc. Exp. Biol. Med. 201:114-118

37. Pilkis, S. J., M. R. El-Maghrabi, and T. H. Claus. 1990. Fructose-2,6 bisphosphate in control of hepatic gluconeogenesis. From metabolites to molecular genetics (published erratum appears in Diabetes Care 1990 Oct 13(10):1098) Diabetes Care. 13:582-599.

38. McGarry, J. D., K. F. Woeltje, M. Kuwajima, and D. W. Foster. 1989 Regulation of ketogenesis and the renaissance of carnitine palmitoyltransferase. Diabetes Metab. Rev. 5:271-284.

39. Kelleher, J. K. 1986. Gluconeogenesis from labeled carbon: estimating isotope dilution. Am. J. Physiol. 250:E296-E305.

40. Garfield, S. A., and R. R. Cardell. 1979. Hepatic glucose-6-phosphatase activities and correlated ultrastructural alterations in hepatocytes of diabetic rats Diabetes. 28:664-679.

41. Barzilai, N., and L. Rossetti. 1993. Role of glucokinase and glucose-6phosphatase in the acute and chronic regulation of hepatic glucose fluxes by insulin. J. Biol. Chem. 268:25019-25025.

42. Jeng, C-Y., W. H-H. Sheu, M. M-T. Fuh, Y-D. I. Chen, and G. M. Reaven 1994. Relationship between hepatic glucose production and fasting plasma glucose concentration in patients with NIDDM. Diabetes. 43:1440-1444. 